\title{
Arte contemporânea é arte pós-conceitual
}

Peter Osborne*

RESUMO: Este ensaio expõe o sentido da proposição especulativa "arte contemporânea é arte pós-conceitual." Partindo de uma elaboração conceitual do contemporâneo como uma forma disjuntiva do tempo histórico (como ideia, problema, ficção, e realidade globalmente transnacional), ele passa a dar um relato das convergências e mudanças que se reforçam mutualmente no caráter da obra de arte e nas relações sociais dos espaços artísticos. Trata-se da tradução da conferência realizada na Fondazione Antonio Ratti, Villa Sucota, Roma, Itália, em 9 de Julho de 2010.

PALAVRAS-CHAVE: Contemporâneo, pós-conceitual, transnacional.

ABSTRACT: This essay expounds the meaning of the speculative proposition 'contemporary art is postconceptual art'. Setting out from a conceptual elaboration of the contemporary as a disjunctive form of history time (as idea, problem, fiction, and globally transnational actuality), it proceeds to give an account of convergent and mutually reinforcing changes in the character of the artwork and the social relations of art spaces.

KEYWORDS: contemporary, postconceptual, transnational.

*Peter Osborne é Diretor do 'Centre for Research in Modern European Philosophy' (CRMEP), Kingston University Londres, e por muito tempo foi editor do periódico britânico Radical Philosophy. Entre seus livros estão The Politics of Time: Modernity and AvantGarde (1995; 2011) and Anywhere or Not at All: Philosophy of Contemporary Art (2013). 
Eu vou apresentar a vocês, de modo conceitualmente conciso, uma espécie de fragmento polêmico de um trabalho sobre construção de um conceito crítico de arte contemporânea. É importante observar que este é um conceito 'crítico', mais do que descritivo ou empírico. Não abrange toda a arte que se chamaria a si mesma de 'contemporânea', mas deriva, impondo-Ihe não obstante algumas exigências críticas, de tal arte. Assim, este conceito está por ser construído, mais do que simplesmente ser descoberto. Ele obtém sua apresentação mais condensada na proposição que serve aqui como meu título: 'Arte contemporânea é arte pós-conceitual'. Eu apresento-lhes esta sentença como uma proposição filosófica - ou ao menos, uma interpretação filosófica de uma situação histórica, já que, afinal, o que é a filosofia senão 'o seu próprio tempo compreendido no pensamento'? Mais especificamente, e talvez de uma maneira inquietante, eu ofereço-lhes este conceito como uma proposição especulativa, no sentido técnico em que essa expressão é utilizada na filosofia de Hegel. Neste sentido, o movimento do pensamento que estabelece a identidade dos elementos dentro de uma proposição filosófica é dirigido à destruição da 'natureza geral do julgamento', baseado na distinção entre sujeito e predicado, de tal modo que, como um resultado da profundidade especulativa da identidade proposta, 'o sujeito desaparece no [ou é exaurido por] seu predicado'. Desse modo, ao inverter a proposição ('Arte pós-conceitual é arte contemporânea'), o predicado torna-se o sujeito e é, por sua vez, destruído como tal. Assim, há um infinito movimento do pensamento entre os dois termos em uma proposição especulativa, em relação à qual a própria proposição (predicação) é, nas palavras de Hegel, 'uma mera forma vazia' (HEGEL, 1976, p 60-66).

Portanto, a identidade dos elementos, que destrói a forma proposicional, não destrói a diferença entre eles. Antes muito mais, ela revela que esta diferença é a do movimento de certa 'unidade' ou 'harmonia' que emerge da uniformização da própria diferença. É através da experiência da proposição especulativa (experiência especulativa) que - de um modo proto-primeiro Romântico, não-proposicional - a filosofia hegeliana aproxima-se da experiência da arte. No entanto, ela o faz apenas no fim de um processo muito longo por meio do qual o significado dos elementos em causa - no nosso caso aqui, 'arte contemporânea' e 'arte pós-conceitual' - são construídos. Devo apresentar-Ihes, aqui, uma mera descrição ou um esqueleto de tal processo de constituição. 
Minha argumentação tem dois componentes principais e dois complementares. Os principais são:

1. o contemporâneo - como ideia, problema, ficção e realidade

2. arte como construção/expressão do contemporâneo, ou, arte pós-conceitual

Os itens complementares dizem respeito a certa necessidade de:

3. ficcionalização da autoridade do artista e

4. coletivização de ficções artísticas.

Essas duas últimas seções tomam o trabalho do Grupo Atlas (1999-2005) - Walid Raad na sua fachada como Grupo Atlas - como um exemplar de suas preocupações. (Por isso a imagem que abre esta palestra, do trabalho em vídeo de 2015 do Grupo Atlas, We can make rain, but nobody came to ask.) A ideia geral, entretanto, é expor vários aspectos da arte contemporânea na sua generalidade crítica, como pedaços de um quadro interpretativo filosófico. Então começarei pelo maior nível de abstração, e abrirei caminho em direção - sem nunca, aqui, finalmente chegar - ao concreto: do abstrato ao concreto, como Marx notadamente recomendou em suas notas metodológicas na introdução dos Grundrisse. Neste caso: da filosofia à arte.

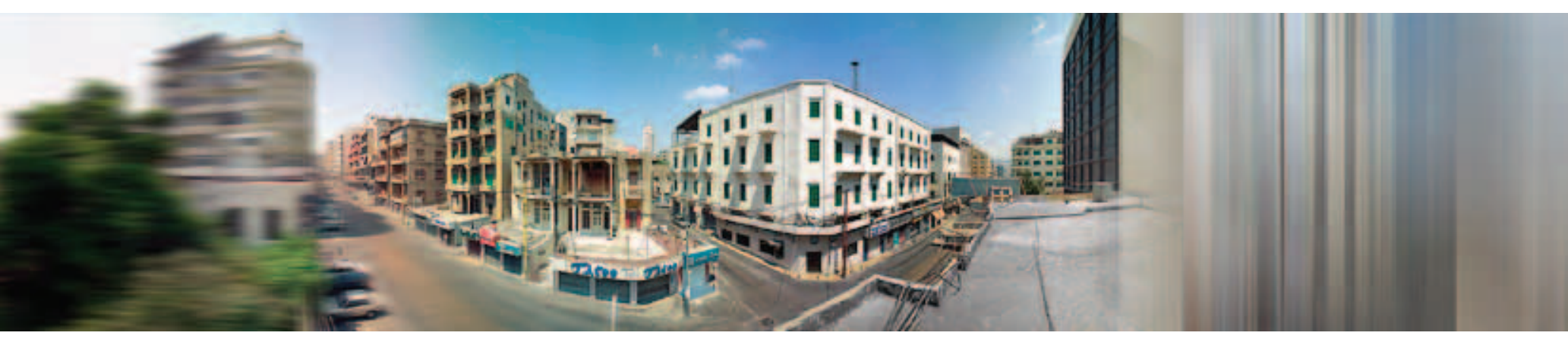

\section{Walid Raad/Atlas Group}

Still de We can make rain again but no one came to ask, 2003/2006

Projeção DVD, Cor, 18 minutos. Cortesia Paula Cooper Gallery. 


\section{1. $O$ contemporâneo como ideia, problema, ficção e realidade}

\section{Ideia}

Em sua acepção mais básica, o conceito de contemporâneo é o da coexistência, a unidade na disjunção ou, a unidade disjuntiva, dos tempos. Em termos concretos, ele refere-se à coexistência dos ciclos das vidas humanas dentro do tempo da existência. Contemporâneos são aqueles que vivem (ou viveram) o mesmo tempo. (Curioso que o termo 'contemporâneos' seja primeiramente utilizado com o verbo no pretérito perfeito: 'nós fomos contemporâneos'. A afirmação 'nós somos contemporâneos' é redundante, dado que é performaticamente tautológica). Por ser um conceito histórico, o contemporâneo, implica, desta forma, em uma projeção da unidade para a totalidade diferencial dos tempos das vidas que estão, em princípio, ou potencialmente, presentes umas às outras de algum modo, em um tempo particular - e, em particular, 'agora', dado que é o presente vivido que estipula o modelo da contemporaneidade. Ou seja, o conceito de contemporâneo projeta um tempo histórico único do presente, como um presente vivido - um tempo histórico comum, embora internamente disjuntivo, das vidas humanas. 'O contemporâneo', em outras palavras, é uma forma abreviada para 'o presente histórico'. Tal ideia é inerentemente problemática, mas cada vez mais irresistível.

\section{Problemas}

É problemática, em primeiro lugar, teoreticamente, porque é uma ideia, no sentido técnico de Kant, de ser um objeto além da experiência possível (a conjunção total dos tempos vigentes) (KANT, 1997, pp. 394-408). Em segundo lugar, de modo ainda mais fundamental, por razões filosófico-temporais de um tipo primeiro Heidegger: nomeadamente, que o próprio 'presente', por si só na sua presentidade, não é dado na experiência como tal, dado que ele só ex-iste como a diferenciação ou a união fraturada dos outros dois modos temporais (passado e futuro), sob a prioridade da sua dimensão de futuro' (HEIDEGGER, 1962).

O conceito de contemporâneo, assim, projeta na presença uma unidade temporal que é, em princípio, relativa ao futuro ou ao horizonte e, por isso, ele é especulativo. Finalmente, em terceiro lugar, empiricamente, a totalidade relacional dos tempos coetâneos atuais da existência humana permanece, fundamentalmente, disjuntiva socialmente. Portanto, não há nenhuma 
posição-sujeito atualmente partilhada de (ou dentro de) nosso presente do ponto de vista do qual sua totalidade relacional poderia ser construída como um todo, mas em uma forma temporariamente fragmentada ou dispersa ou incompleta.

\section{Ficção}

Contudo, a ideia do contemporâneo funciona como se existisse. Isto é, ela funciona como se o horizonte especulativo da unidade da história humana tivesse sido alcançado. A este respeito, o contemporâneo é uma ideia utópica, com seus aspectos positivos e negativos. Negativamente, envolve uma recusa; positivamente, é um ato da imaginação produtiva. Ela envolve uma recusa - uma recusa de sua própria base especulativa ligada ao futuro - na medida em que projeta uma conjunção de tempos real. Essa é uma recusa da possibilidade de futuro do presente por sua própria presentidade; fundamentalmente, trata-se de uma recusa da política. Ela é um ato produtivo da imaginação na medida em que projeta performativamente uma unidade não-existente para as relações disjuntivas entre tempos coetâneos. A este respeito, ao tornar presente o tempo ausente de uma união de tempos, todas as construções do contemporâneo são ficcionais. Mais especificamente, o contemporâneo é uma ficção operativa: ela regula a divisão entre o passado e o presente (através do seu sentido de futuro) dentro do presente. Epistemologicamente, pode-se dizer que o contemporâneo marca o ponto de indiferença entre a narrativa histórica e ficcional que tem sido associada, desde a crítica de Hegel, com a noção da própria experiência especulativa² (RICOEUR, 1988, p. 99-240).

É a 'presentidade' ficcional do contemporâneo que o distingue da categoria mais estruturada e duradoura da modernidade, o caráter inerente de autossuperação que o identifica com uma transitoriedade permanente familiar na crítica literária desde Baudelaire. A esse respeito, o contemporâneo envolve um tipo de abrigo interno do moderno no presente. Como um comentador recentemente colocou, a contemporaneidade é 'o presente impregnado do sentido original de moderno, porém sem o seu subsequente contrato com o futuro' (SMITH, 2006, p. 681-707). Essa copresentidade fictícia de uma multiplicidade de tempos associa o contemporâneo - em um nível conceitual profundo - a uma cultura teológica da imagem. Na famosa frase de Michael Fried - de qual todo o sentido do imaginário, do caráter fictício da experiência está ausente - 'presentidade é graça'3 (FRIED, 1998, p.168). 
Se a modernidade projeta um presente em permanente transição, o contemporâneo fixa ou abarca essas transitoriedades dentro da duração de uma conjectura, ou, mais amplamente, o invólucro de uma vida. Essa presentidade encontra sua forma representacional na aniquilação da temporalidade pela imagem. É na cultura da imagem fotográfica e pós-fotográfica que a contemporaneidade do contemporâneo fica expressa mais claramente. A imagem interrompe igualmente as temporalidades do moderno e da natureza. O contemporâneo aparece como 'heterocrônico' relativamente a esses padrões normativos: um tempo 'anormal' de ocorrências irregulares, ou no termo de Nietzsche um tempo 'inatual' (unzeitgemässe). Heterocronia é a dimensão temporal de uma heteronomia geral, ou uma multiplicidade de determinações. Ela marca simultaneamente o momento da disjunção (e consequente o antagonismo) dentro da unidade disjuntiva do presente histórico e o modo disjuntivo existencial da própria presentidade (HERNANDEZ-NAVARRO, 2008, p. 9).

Além disso, essa unidade disjuntiva e antagonista do contemporâneo não é apenas temporal, mas igualmente (na verdade, em certos aspectos, primeiramente) espacial. Este é o segundo ponto principal da problemática teórica do contemporâneo: o problema da unidade disjuntiva dos tempos sociais é o problema da unidade e da disjunção do espaço social - isto é, em sua forma mais ampla, o problema da geopolítica. A ideia do contemporâneo coloca o problema da unidade disjuntiva do espaço-tempo, ou do geopoliticamente histórico. Se se quer retirar algum sentido a partir da noção do historicamente contemporâneo, deve-se considerar que dialética temporal do novo, que dá definição qualitativa ao presente histórico (como o ponto de vista a partir do qual sua unidade é construída) - mas que com a noção do contemporâneo elimina do futuro -, deve ser mediada pela complexa dialética global dos espaços. Ou, para colocar de outro modo, a ficção do contemporâneo é necessariamente uma ficção geopolítica. Isso complica consideravelmente a questão da sua periodização, ou a extensão da duração do contemporâneo 'em sentido oposto', em direção ao passado cronológico recente. Essa extensão da duração do contemporâneo (como uma unidade projetada dos tempos das vidas atuais) impõe uma dinâmica de periodização em constante mudança que insiste na questão de quando o presente começa. E é possível encontrar repostas muito diferentes para essa questão, dependendo de onde se está pensando geopoliticamente (CAMNITZER, 2007).

Dessa forma, alguém poderia dizer, 'Para Cada Presente, Sua Própria Pré-história': significando, para cada construção geopolítica diferenciada do presente como um todo, há sua própria 
pré-história. Pois apesar dos problemas teóricos do caráter fictício da unidade e do ponto de vista espacial, as construções do contemporâneo parecem cada vez mais como inevitáveis porque as crescentes interconexões sociais globais proveem conteúdo significativo a essas ficções, preenchendo suas projeções especulativas com material empírico ('fatos'), efetuando dessa maneira a transição da narrativa ficcional para a histórica. Nesse âmbito, o conceito do contemporâneo adquiriu a necessidade regulativa de uma 'ideia' kantiana. Cada vez mais, 'o contemporâneo' tem o status transcendental de uma condição de inteligibilidade histórica da própria experiência social.

\section{Realidade: o contemporâneo hoje ou o transnacional global}

Cada vez mais, então, a ficção do contemporâneo é primordialmente uma ficção planetária ou global. Mais especificamente, a ficção de uma transnacionalidade global deslocou recentemente 140 anos da hegemonia de um imaginário internacionalista, 1848 - 1989, que veio em uma variedade formas políticas. Essa é uma ficção - uma projeção da unidade temporal do presente ao redor do planeta - baseada na interpenetração contraditória das formas sociais herdadas ('comunidades', 'culturas', 'nações', 'sociedades' - todas estas formulações cada vez mais inadequadas) pelo capital, e suas consequentes interconexão e dependência forçadas. Resumindo, hoje, o contemporâneo (a fictícia unidade relacional do presente histórico) é transnacional porque nossa modernidade tem uma tendência em direção ao capital global. A transnacionalidade é a suposta forma socioespacial da corrente unidade temporal da experiência histórica.

Como Gayatri Spivak argumentou o queToby Volkman, coordenador de programas da Fundação Ford, descreve como 'saltos demográficos, diásporas, migrações relacionados ao trabalho, os movimentos do capital e mídia globais, e processos de circulação cultural e hibridização' (VOLKMAN, 1999, p. 9) têm gerado o duplo imaginário geopolítico de um nacionalismo cultural pós-colonial e um multiculturalismo metropolitano, na melhor das hipóteses, problemático e, na pior, redundante. Spivak contra-argumenta:

O que podemos observar no mundo globalizado e pós-colonial é o retorno das fronteiras demográficas, mais que territoriais, que precedem e que são maiores que o capitalismo. Essas fronteiras demográficas, que responde à migração em larga escala, estão agora apropriando a 
versão contemporânea de uma realidade virtual e criando tipos de coletividades paraestatais que pertenciam aos mutáveis impérios multiculturais que precederam o capitalismo monopolista (SPIVAK, 2003, p. 3 e 15).

Fronteiras ou limites territoriais (basicamente, estados-nações) estão sujeitos a se esfacelar pela 'globalização' de dois modos. Primeiro, elas possuem uma crescente, embora ainda fisicamente restrita, 'permeabilidade'. 'Fronteiras são facilmente ultrapassadas a partir dos países metropolitanos, enquanto tentativas de entrada a partir dos chamados países periféricos ainda encontram fronteiras burocráticas e policiais mais difíceis de penetrar de um modo geral' (SPIVAK, 2003, p. 16). As pessoas quase sempre cruzam as fronteiras da chamada periferia para o metafórico centro apenas como um capital variável - incluindo o trabalho em arte. (A arte é um tipo de passaporte. Nos espaços transnacionais, é encenada uma utopia do mercado de livre circulação, enquanto na realidade ela incorpora a contradição da mediação dessa circulação pelo capital.) Segundo, a tecnologia da informação torna possível a construção de novos sujeitos sociais, e a manutenção da unidade dos sujeitos mais antigos e fragmentados, por meio das fronteiras nacionais, em uma nova maneira.

Mas como essa contemporaneidade geopoliticamente complexa deve ser experimentada ou representada? E, em particular, como isso pode ser experimentado através ou como arte? O problema é menos 'representação' do que 'apresentação' (menos Vorstellung do que Darstellung): a interpretação do que acontece através da construção de novas totalidades a partir dos seus fragmentos e modalidades de existência. Isso é tanto manifestação de um desejo de contemporaneidade - para forçar conjuntamente a multiplicidade dos tempos sociais coetâneos - quanto é uma questão de representação.

\section{Arte como construção/expressão do contemporâneo, ou, arte pós-conceitual}

Que dizer da 'arte contemporânea'? A arte é uma mensageira cultural privilegiada da contemporaneidade, tal como se deu com as formas precedentes da modernidade. Em decorrência da expansão histórica, diferenciação geopolítica e intensificação temporal da contemporaneidade, tornou-se praticamente obrigação para qualquer arte com uma reivindicação sobre o presente, posicionar-se, reflexivamente, no interior deste campo expandido. A coexistência de diferentes tempos que constitui o contemporâneo, e as relações entre os espaços 
sociais nos quais estes mesmos tempos estão incorporados e articulados, são os dois eixos principais junto aos quais o significado histórico da arte deve ser traçado. Como resposta a esta condição, nos últimos anos, as características inter- e transnacional de um espaço de arte transformaram-se nas marcas principais da sua contemporaneidade. Neste processo, as instituições de arte contemporânea ganharam um grau sem precedentes de autoconsciência histórica e criaram um novo tipo de espaço cultural - tendo a bienal internacional como seu emblema já ineficaz - dedicado à exploração, por meio da arte, das semelhanças e diferenças entre as formas geopoliticamente diversas de experiência social que só recentemente começaram a ser retratadas dentro das normas de um mundo comum.

Mais particularmente, as instituições internacionais de arte são os representantes culturais de uma ideia de mercado de um sistema global de sociedades. Elas mediam as relações de troca com os artistas, através dos mais recentes discursos culturais da 'globalização', a fim de colocar a última versão do contemporâneo na vitrine. Em consequência de seu poder de reunião, as bienais internacionais revelam o poder econômico-cultural do 'centro' aonde quer que elas despontem, não importando o que está sendo exposto. Em suma, elas são uma ramificação de Pesquisa e Desenvolvimento da transnacionalização da indústria cultural. As novas bienais internacionais são emblemas da capacidade do capital em atravessar fronteiras e de acomodar e apropriar as diferenças culturais. O trabalho artístico é um capital cultural variável. Além disso, atualmente, só é capital aquilo que de modo imanente projeta o horizonte utópico de um encadeamento social e global, na última forma distópica do mercado.

Entretanto, para todas estas definições sociais, ainda é o caráter artístico das obras em exposição - suas maneiras particulares de exibir sua lacuna individual de autoevidência - que torna tudo isso possível, e a ergue ao status de uma série estendida de exibições mundiais. Particularmente, ele é a última extra-territorialidade da arte (um componente essencial da sua ilusão de autonomia) que torna possível as múltiplas e mais recentes, além de complexas, territorializações das instituições de arte. Para que a arte assuma uma crítica dentro destas instituições, como uma construção/expressão do contemporâneo - ou seja, para que ela se aproprie do poder de temporalização da imagem como a base para novas temporalizações históricas - ela deve relacionar-se diretamente com a ontologia sócioespacial dos seus próprios locais e relações internacional e transnacional. Neste ponto, a significação histórica e crítica da transformação da ontologia da obra de arte, realizada ao longo dos últimos 50 anos, de 
uma ontologia artesanal dos médiuns para uma ontologia, pós-conceitual, transcategórica, de materializações, atinge o estágio de maturidade.

Isto me leva à minha tese principal: é a convergência e o condicionamento mútuo das transformações históricas na ontologia da obra de arte e as relações sociais do es-

paço artístico - uma convergência e um condicionamento mútuo que têm suas raízes nos processos econômicos e comunicacionais mais gerais - aquilo que torna possível a arte contemporânea, no sentido enfático de uma arte da contemporaneidade. Estas transformações convergentes e mutuamente condicionadas assumem a forma comum de processos de 'des-fronterização': por um lado, a des-fronterização das artes como médiuns - a emergência de práticas genuinamente transcategóricas dando abertura ao espaço conceitual de uma arte 'genérica' - e por outro, a des-fronterização dos espaços anteriormente nacionais e sociais da arte. Isso tem sido um processo histórico extraordinariamente complexo. Todavia, seu efeito pode ser resumido, em suma, como a aparência imanente na obra de arte da dialética global sócioespacial dos lugares, não-lugares e fluxos, apresentados numa constelação dialética de aspectos estéticos, conceituais e distributivos da arte. É esta formação dialética que constitui o que chamo de caráter 'pós-conceitual' da arte contemporânea.

Essa arte tem seis características principais:

1. Uma relevante - porém, indevida - conceitualização. (Arte é composta por conceitos, suas relações e sua iniciação em práticas de segregação: arte/não-arte.)

2. Uma relevante - porém, inadequada - dimensão estética. (Toda a arte reclama alguma forma de materialização; isto é, forma [=espaço-temporal] estética.)

3. Uma função antiestética de materiais estéticos. (Este é um pré-requisito importante da imperiosa conceitualização da arte.)

4. Uma dilatação exorbitante dos possíveis meios materiais da arte. (Transcategorialidade) Este é o sentido emancipador da condição 'pós-médium'.

5. Uma completa equânime - a saber, irredutivelmente relacional - unidade de obras de arte de um indivíduo, através da totalidade das numerosas iniciações materiais, em dado momento. (Uma ontologia das materializações.)

6. A maleabilidade histórica das fronteiras dessa unidade (OSBORNE, 2004, p.651-670) 
É a junção das duas primeiras características que levam à terceira e à quarta, enquanto a quinta e a sexta são manifestações de suas consequências lógicas e temporais, respectivamente.

Em suma, a arte contemporânea é 'pós'-conceitual na medida em que registra a experiência histórica da arte conceitual, como um movimento autoconsciente, como a experiência da impossibilidade/falácia da absolutização do antiestético, considerado juntamente com o reconhecimento de um aspecto conceitual que não pode ser eliminado de qualquer arte. Com respeito a isso, a arte é pós-conceitual no grau em que ela incorpora reflexivamente a verdade (que, por sua vez, incorpora a não verdade) da 'arte conceitual': ou seja, a arte é, forçosamente, ao mesmo tempo estética e conceitual.

O caráter espacial dessa dialética do estético e do conceitual - e seu significado social e ontológico como uma expressão artística da dialética dos lugares e não-lugares - aparece mais claramente na arte do final dos anos 1960 e início dos anos 1970 nas práticas de sua textualização, de sua arquiteturização ou ambientalização. Naquela época, Robert Smithson concebeu esta prática dupla como a dialética do site e non-site. Sua transformação mais recente, por meio de outra complicação dessa dialética pela emergência de um novo 'espaço de fluxos', aparece no processo da transnacionalização da arte. Isso revela que o processo de transnacionalização acontece, de forma fundamental, no nível da ontologia histórica da arte o seu ser como arte - e não apenas ao nível das suas formas de distribuição.

A esse respeito, a transnacionalização representa um quarto estágio na narrativa histórica da ampliação do alcance espacial e concepção de arte ocidental do século XX, que pode ser resumida da seguinte forma: a espacialidade euclidiana dos objetos para a espacialidade especulativa das relações planetárias.

1. A ambientalização da pintura e da escultura, de Matisse a Kaprow, passando pelo muralismo, até chegar ao investimento dos minimalistas do espaço negativo. (Este é um movimento ainda assentado no interior, nas relações entre objetos e salas.)

2. A textualização, a arquiteturalização e a ambientalização ampliada da arte, e a criação de um conceito genérico de arte, através da exploração da ambiguidade constitutiva da relação entre planta/edifício ou conceitualização/materialização. (Este é o momento de Lewitt, Bochner, Graham, Smithson e Matta-Clark - e, certamente, Hans Haacke.) 
3. O urbanismo pós-arquitetural de vários tipos de trabalho para o projeto e a nova definição funcional de lugar, baseados na conscientização do papel constitutivo dos não-lugares. (Mark Dion e Réne Green podem ser, aqui, citados como exemplos.)

4. A transnacionalização da arte por meio de sua produção para e inscrição dentro de um espaço transnacional de arte que intermedia a dialética global dos lugares, não lugares e fluxos, através de formas institucionais da exposição internacional em larga escala, do mercado e da migração de artistas. (Este é o momento no qual tomarei O Grupo Atlas como o meu modelo.) É um processo profundamente contraditório no qual os artistas e formas mercadológicas e institucionais de arte negociam a política do regionalismo, do nacionalismo pós-colonial e da migração, substituindo a lógica espacial geral da obra pós-conceitual pela dinâmica político-econômica global.

Então, como a 'arte' pode ocupar, formular, refletir criticamente e transfigurar assim globalmente um espaço transnacional? Somente, creio, se a posição-sujeito de sua produção for capaz de revelar - ou seja, construir e, assim, expor - algo da estrutura do próprio 'contemporâneo'. O trabalho do Grupo Atlas é emblemático aqui, pois chama a atenção para dois aspectos distintivos e relacionados deste processo: a ficcicionalização e a coletivização especulativa.

\section{A ficcicionalização da autoridade artística (anonimato e a função-autor)}

No trabalho do Grupo Atlas, o relato ficcionalizado atua em dois níveis e assume duas formas principais: a ficcicionalização da autoridade artística ou o que, adaptando Foucault, podemos chamar de 'função-artista', e a ficcionalização da forma documental, em particular, o arquivo. Tal ficcicionalização corresponde e visibiliza a natureza fictícia do próprio contemporâneo. O relato ficcionalizado também explicita certa ficcionalidade geral da obra de arte pós-conceitual, que é um efeito da contrafactualidade inerente à sua dimensão conceitual, e que Ihe transmite um aspecto estruturalmente 'literário'. Toda materialização pode ser entendida como a performance de um elemento fictício ou ideia. A este respeito, o conceito genérico de arte pós-médium reincorpora a 'literatura', restituindo-a às suas origens filosóficas no primeiro romantismo alemão. A arte pós-conceitual articula uma poética pós-estética. 
Historicamente, a ficcionalização da função-artista é, naturalmente, uma estratégia autoral comum. Ela representa uma extensão tanto da estratégia do uso de pseudônimos (preponderante sob condições de censura e no caso de necessidade de dissimulação social de diversos tipos) quanto da 'impessoalidade' de um modernismo do tipo de T.S. Elliot. Teoreticamente, ela é melhor concebida, penso, em termos da análise da função-autor feita por Foucault, que era, em si, de muitas maneiras (como grande parte do pós-estruturalismo), uma teorização das implicações da prática das vanguardas modernistas. Para Foucault, a substituição do conceito de autor pelo de função-autor era 'uma questão de tirar do sujeito (ou seu substituto) o seu papel como criador, e de analisar o sujeito como uma função variável e complexa do discurso... apreendendo os pontos de inserção do sujeito, modos de funcionamento, e o sistema de dependências' (FOUCAULT, 1979, pp.141-160). A construção de uma função-artista denominada 'Grupo Atlas' é, sob muitos aspectos, uma aplicação precisa dos termos desta análise para a produção da autoridade artística. Sua principal característica é a sua falta de semelhança com uma prática documental.

Isso depende, em primeiro lugar, do uso criativo do anonimato, dentro da utilização de pseudônimos, através da forma 'Grupo' (o uso de pseudônimos, poderíamos afirmar, é uma condição da ficcionalização histórica); e, em segundo lugar, o estudo da documentação simultaneamente como uma marca indicial e como uma forma cultural pura. Mais profundamente, para a sua ambiguidade produtiva na relação entre as narrativas ficcionais e históricas, ele liga uma ambiguidade que encontra seu ponto de indiferença no conceito de especulação, através do qual ele alcança ao mesmo tempo a sua força política e filosófica. Por um lado, essa ambiguidade é típica de uma prática que utiliza narrativas ficcionais para finalidades históricas e críticas; por outro, uma demarcação interna rigorosa entre o uso indicial e o puramente formal (isto é, ficcional) de documentos é marcada por cronologias sistematicamente aberrantes e contradições narrativas - um procedimento que é por vezes aplicado à narração da formação do próprio 'Grupo Atlas', cuja especificação varia do ano de 1999, ao ano de 1977 e ao período compreendido entre 1986-1999. (1999 foi o ano real). É na relação entre a coletividade anônima da ficção do próprio 'Grupo Atlas', e a faceta nacional de suas ficções ('Líbano') que repousa tanto o caráter transnacional quanto o significado político de sua prática. 


\section{A coletivização das ficções artísticas (ou a coletividade especulativa do transnacional)}

Coletivos artísticos (ficcionais ou verdadeiros) estão na moda novamente. Eles estão proliferando rapidamente através da comunidade artística internacional, seja de forma singular ('Claire Fontaine', por exemplo) seja de modo explicitamente coletivo (Raqs Media Collective). Há, ainda, uma nova historiografia revisionista do passado recente deles ${ }^{4}$. Existe uma variedade de razões para isto, sendo que a maioria delas relaciona-se com as tentativas de remodelar os modos de efetividade nas relações entre política e arte. Minha tese é que o fenômeno dos coletivos artísticos tem uma nova função aqui ligada à sua ficcionalização, no momento do transnacionalismo global, do qual o recente aumento no número de coletivos (fictícios ou não) é um sinal involuntário.

A coletivização da ficcionalização da função-artista funciona, mais uma vez, em dois níveis: a coletividade do Grupo, e a coletivização da autoridade inerente (nesse caso, ficcionalizada) na forma documental - no limite, a 'coletividade' material da própria indicialidade, o poder significante da natureza. A ligação é o anonimato. É através da combinação de anonimato e referência inerente no pseudônimo 'O Grupo Atlas', com suas conotações globais, que a sua coletividade fictícia aparece na própria coletividade especulativa do transacional global.

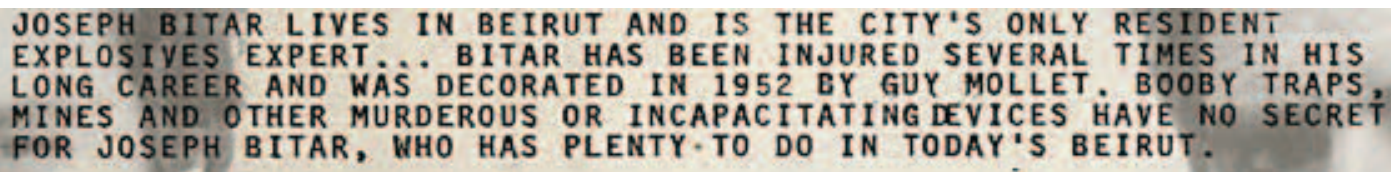

\section{Walid Raad/Atlas Group}

Still de We can make rain again but no one came to ask, 2003/2006

Projeção DVD, Cor, 18 minutos. Cortesia Paula Cooper Gallery. 
Reivindiquei antes que, no tempo atual, é apenas o capital que de modo imanente projeta o horizonte utópico da interconectividade social global, na forma distópica do mercado: apenas o capital manifesta uma estrutura-sujeito em nível global. Porém, a sociabilidade capitalista (o fundamento das sociedades em relações de troca) é essencialmente abstrata; é uma questão de forma, mais do que 'coletividade'. A coletividade é produzida através da interconexão dos trabalhos, mas a interconexão e dependência universal que o capital produz exibem a estrutura de um sujeito (a unidade de uma atividade) apenas objetivamente, nos seus produtos, separados dos sujeitos individuais e das coletividades particulares do trabalho, no autodesenvolvimento da forma-valor. Historicamente, é claro, o nacionalismo (a ficção cultural das nações) preencheu essa lacuna. Nações ('comunidade imaginadas') têm sido sujeitos sociais privilegiados de capitais competitivos. Todavia, a estrutura-sujeito do capital não mais corresponde à especificidade territorial dos estados-nações, e outras sociedades fora do nexo do capital global estão sendo sugadas inexoravelmente para dentro dele. Nesse aspecto, a coletividade imanente do capitalismo permanece, e vai sempre permanecer, estruturalmente, 'por vir'. Por isso, o caráter abstrato e totalmente formal de sua mais recente antecipação como 'multidão'. A coletividade ficcional do Grupo Atlas e seus 'carácteres' narrativos são um substituto para a ausente coletividade política do transnacional global, que é duplamente positivado e negado pelo próprio capital. Como tal, ele corresponde, em um nível estrutural, com o trabalho de 'autores' como Luther Blissett e Ming Wu no campo da literatura. Politicamente, poder-se-ia dizer, que esse trabalho representa, pela virtude de suas relações efetivas com a história filosófica do capital, a continuação da tradição intelectual do internacionalismo marxista através dos novos meios artísticos transnacionais. O Grupo Atlas pode ser descrito como o representante artístico de uma espécie de 'Primeira Transnacional'.

Mas o que, então, a partir do foco especificamente nacional do trabalho do Grupo Atlas, é exclusivamente ficção Libanesa? Minha afirmação aqui é que a ficcionalização do 'Líbano' através da ficcionalização da evidência de sua existência - afeta uma ficcionalização emblemática do próprio nacional. Além disso, esta ficcionalização dos atos nacionais como a condição desnacionalizante de sua transnacionalização; uma transnacionalização que é efetuada através da estrutura sócioespacial da obra de arte/ mundo. Isto não é o transnacionalismo como o outro abstrato da nação, mas a transnacionalização como a mediação da forma da nação com o seu outro global abstrato. No horizonte desse movimento, podemos captar algo do aspecto 
democrático-radical da projeção de Foucault de uma possível substituição da função-autor por alguma forma de anonimato. Isto evoca a pergunta retórica que termina o famoso ensaio de Foucault: "'Que diferença faz quem está falando?'”.

\section{Notas}

1 Temporality, for Heidegger, 'has the unity of a future which makes present in the process of having been.' (Temporalidade, para Heidegger, 'contém a unidade de um futuro que torna presente no processo de ter sido').

2 Embora o volume dos seus escritos sobre tempo e história, em nenhum lugar Ricoeur tematiza o conceito de contemporâneo. O mais perto que ele chega na sua pequena discussão da "'nossa Modernidade'" é em History, Memory, Forgetting, Chicago: University of Chicago Press, 2004, trans. Kathleen Blamey and David Pellauer, p. 305-314.

3 Eu discuto o caráter teleológico da imagem fotográfica in: Peter Osborne, Philosophy in Cultural Theory, Ch. 2, 'Sign and Image'.

4 Ver, por exemplo, Blake Stimson and Gregory Sholette, eds, Collectivism After Modernism: The Art of Social Imagination After 1945, University of Minnesota Press, Minneapolis, 2007.

\section{Referências}

CAMNITZER, Luis. Conceptualism in Latin American Art: Didactics of Liberation, Austin: Texas University Press, 2007.

FOUCAULT, Michel. 'What is an Author?' (1969), In: HARARI Josué V., ed., Textual Strategies: Perspectives in Post-Structuralist Criticism, Ithaca: Cornell University Press, 1979.

FRIED, Michael 'Art and Objecthood' (1967), In: Art and Objecthood: Essays and Reviews. Chicago: University of Chicago Press, 1998. KANT, Immanuel Kant, Critique of Pure Reason, trans. Paul Guyer and Allen W. Wood. Cambridge: Cambridge University Press, 1997. HEIDEGGER, Martin Being and Time (1927), trans. John Macquarrie and Edward Robinson, Oxford: Blackwell, 1962.

HEGEL, G.W.F. Phenomenology of Spirit, trans. A.V.Miller, Oxford: Oxford University Press, 1976.

HERNANDEZ-NAVARRO, Miguel Ángel 'Presentacíon. Antagonismos Temporales', Heterocronías: Tiempo, Arte y Arqueologías del Presente, Murcia: CENDEAC, 2008.

OSBORNE Peter, 'Art Beyond Aesthetics: Philosophical Criticism, Art History and Contemporary Art' In Art History, Volume 27, no. 4, 2004.

RICOUER, P. Time and Narrative, Volume 3, Pt IV, Section 2, 'Poetics of Narrative: History, Fiction, and Time'., trans. Kathleen Blamey and David Pellauer. Chicago: University of Chicago Press, 1988.

SMITH, Terry, 'Contemporary Art and Contemporaneity' In: Critical Inquiry 32 (Summer 2006).

SPIVAK, Gayatri Chakravorty, Death of a Discipline, Columbia University Press, New York, 2003, pp. 3 and 15.

VOLKMAN, Toby Alice, Crossing Borders: Revitalizing Area Studies, New York: Ford Foundation, 1999. 